\title{
Mechanical Characteristics of Concrete Bottom Slab in Elevated Pile Cap Steel Boxed Cofferdam in a Bridge
}

\author{
Wenjing Wang ${ }^{1, a}$, Bin Liang ${ }^{1, b}$, Weiwei Chen ${ }^{1, c}$ \\ ${ }^{1}$ Civil Engineering School, Henan University of Science and Technology, Luoyang 471023, China \\ a742094540@qq.com, ${ }^{\mathrm{a}}$ liangbin4231@163.com, ${ }^{\mathrm{c}}$ 1278216732@qq.com
}

\begin{abstract}
Keywords: bridge engineering, elevated pile cap foundation, steel boxed cofferdam, concrete bottom slab, force analysis
\end{abstract}

Abstract. Mechanical characteristics of concrete bottom slab in elevated pile cap steel boxed cofferdam in a bridge is studied. Taking Yuanshui bridge as an engineering example, the loading process of a precast reinforced concrete bottom slab, a part of a steel suspension box cofferdam using dry sealing and embosoming an elevated pile cap, is analyzed by means of FEM numerical simulation. The model built simulates the changes of the stress and deformation of the slab in each construction phase. The results show that the safety of construction process is ensured by thickening some parts with high stress and large deformation around the pile hole in the slab formwork. Meanwhile, instead of steel formworks, precast slab-forms for the cofferdam don't need disassembling and steel is saved. At the same time it speeds up the construction progress and reduces the cost.

\section{Introduction}

Steel boxed cofferdam is designed for the platform construction of the temporary block water structure. Its role is through the side plate of hanging box cofferdam and the cover concrete of bottom plate surrounding water to provide the anhydrous dry construction environment for construction of the pile cap. According to the use of steel boxed function, it can be divided into four parts of bottom, side, inner supporting and hanging system. Among them, the cover concrete is bottom formwork of the pile caps construction and hanging box side plates is side template of steel boxed construction $[1,2]$.

Although the steel boxed cofferdam is a temporary structure, its safety and periodic structures are very important. The bottom formwork of the reinforced concrete in construction process bears the weight of the steel box cofferdam except withstanding gravity load. It relates to the quality and progress of whole engineering [3, 4]. Therefore, this paper will focus on the analysis of stress and deformation of reinforced concrete bottom slab in various stages of construction. It provides the reference for the design of concrete bottom template.

\section{Project Profile}

Yuanshui bridge located on the Xupu to Huaihua Highway across Yuanjiang with total length of $798.12 \mathrm{~m}$. Double thin-wall piers is used in the main bridge pier, foundation for bored piles with diameter of $4 \Phi 220 \mathrm{~cm}$ high pile cap pile foundation structure, center distance of $6.0 \mathrm{~m}$, cap thickness of $3.5 \mathrm{~m}$ and bottoming concrete thickness of $1.0 \mathrm{~m}$.

According to the site conditions and multi comparison, steel boxed cofferdam is adopted in the elevated pile cap construction and reinforced concrete bottom slab is adopted. Concrete grade is C30. Four vertical and horizontal width $30 \mathrm{~cm}$ and $12 \mathrm{~cm}$ thick ribs are set in reinforced concrete bottom of steel boxed cofferdam. $4 \Phi 2.7 \mathrm{~m}$ reserved holes are equipped. The center position is consistent with the pile center. Reinforced concrete floor is divided into 4 blocks of prefabricated. The $20 \mathrm{~cm}$ wet joint in the temporary platform will pour into a whole. $30 \mathrm{~cm}$ wide and $12 \mathrm{~cm}$ thick (inner diameter $2.7 \mathrm{~m}$ ) circular reinforcing rib are set around each steel tube. $\Phi 14$ rebar is set in reinforced concrete slab. Two layer reinforced mesh into $20 \times 20 \mathrm{~cm}$ square structure. $\Phi 16$ rebar is used in a circular rib of steel tube. 


\section{Finite Element Method Numerical Simulation}

Model and boundary conditions. The model will be subject to the actual size of the engineering. Based on the modeling of convenience, precast slab of the same thickness is set first. The position of pile is set in precast slab. Precast concrete slab model is shown in Fig.1. Because six width 10cm and length $30 \mathrm{~cm}$ Steel I-beam are welded in the construction surrounding steel tube to bear the weight of precast concrete panels first, steel tube is fixed in the construction process and the vertical displacement does not occur. Position of steel I-beam in steel tube is shown in Fig.2. So the model of steel tube is not established in this analysis, just leaving the position of welded I-beam. At the corresponding position of I-beam, precast reinforced concrete is fixed. Each direction displacement is constrained.

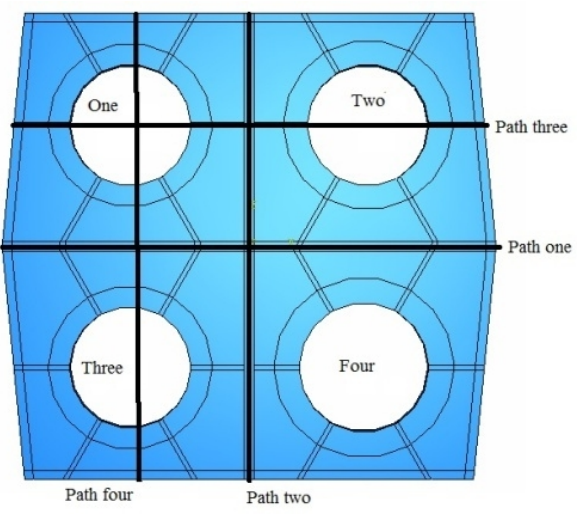

Fig.1 Precast concrete slab model

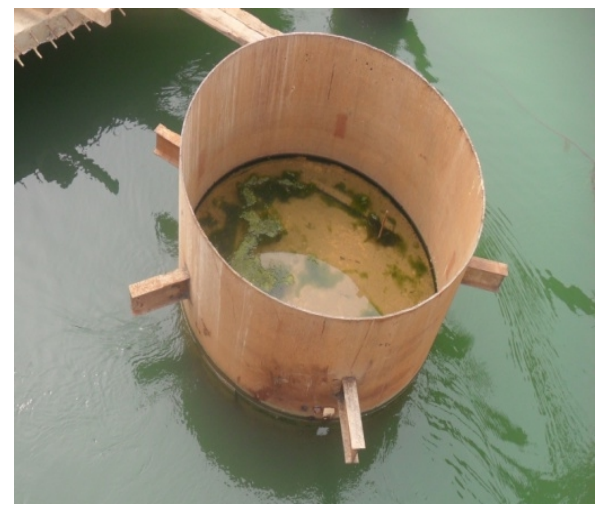

Fig.2 Position of steel I-beam in steel tube

Analysis steps. According to the construction process, the loading process is divided into 5 steps. The first step is applied precast concrete slab deadweight. The Second step is applied steel boxed cofferdam weight. The third step is applied the weight of concrete after the $1 \mathrm{~m}$ cover back. The fourth step is applied a $1.75 \mathrm{~m}$ thick concrete pile cap weight. The fifth step is applied other $1.75 \mathrm{~m}$ thick reinforced concrete cap weight. In fact, when pouring concrete of pile caps, welding I-steel has been cut off. The weight is bear rely on the bond strength between concrete and steel tube and the upward buoyancy of water to bear weight. So the paper only analyses the first three steps and studies the stress and deformation distribution characteristics in the construction process of reinforced concrete plate.

\section{Calculation Results and Analysis}

Analysis of the stress and deformation along path-1. It can be seen from Fig. 3 that the stress of edge part of slab under effect of concrete gravity is minimum. The stress between two reserved pile holes section increases slightly and stress in middle area is relatively small. After applying the load of steel cofferdam and due to steel boxed cofferdam in the edge of concrete plate, it leads the stress of edges in the plate near the location increasing. While because of the role of the constraints, the stress closing to the central plate changes little. After applying the cover concrete weight, plate stress increases significantly. There will be a partial failure if the concrete compressive strength is exceeded.

It can be seen from Fig.4, the deformation of the plate edge is the largest and towards the bottom plate. In the three loads borne by the plate, there is no upward warping deformation appeared which indicates that the end of the restraining plate is reliable. The stress and deformation of the plate on both sides of asymmetric situation is mainly because the division of the grid is not completely symmetrical and stress path from which is the central axis along the plate.

Analysis of the stress and deformation along path-2. It can be seen from Fig.5, the stress of the plate corresponding position in the two reserve pile holes center is the largest. The stress of the plate edges also increases significantly in weight after the application of the cover concrete. The central portion of the stress plate has increased. 
It can be seen from Fig.6, the regularity of deformation curves of along path- 2 and path-1 general are basically the same but the deformation numerical is relatively small. This is mainly due to the asymmetry of the plate itself.

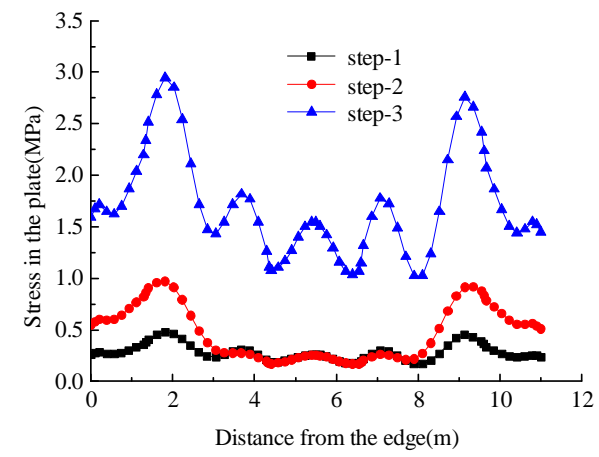

Fig.3 Stress curve along the Path-1 in the plate

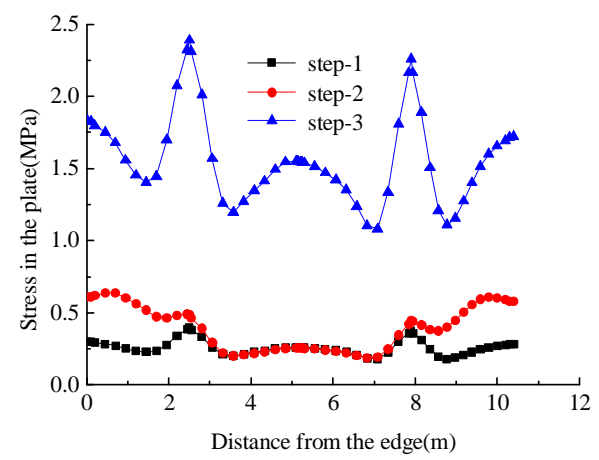

Fig.5 Stress curve along the Path-2 in the plate

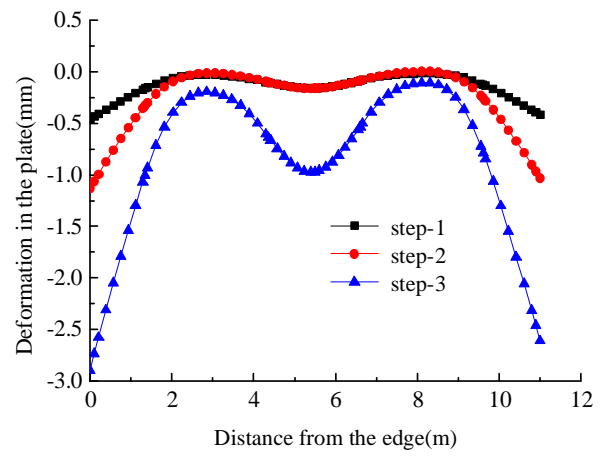

Fig.4 Deformation curve along the Path-1 in the plate

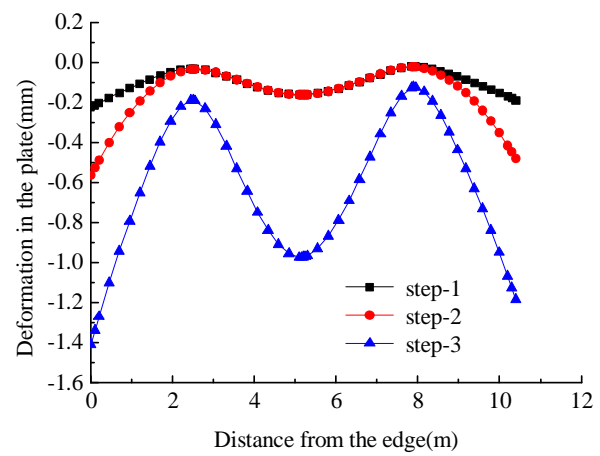

Fig.6 Deformation curve along the Path-2 in the plate

Analysis of the stress and deformation along path-3. It can be seen from Fig.7, the edge portion of the reserved empty stress is larger. The corresponding constraint of corresponding position in the lower part of the plate limits plate deformation, resulting in the rise of the stress in plate. Close to the edge section, stress is higher significantly than near the central position. The stress of the two reserve hole in the middle plate is relatively larger.

It can be seen from Fig.8, the position of the plate edge vertical deformation is the largest. Position between the two reserve pile holes deformation is smaller.

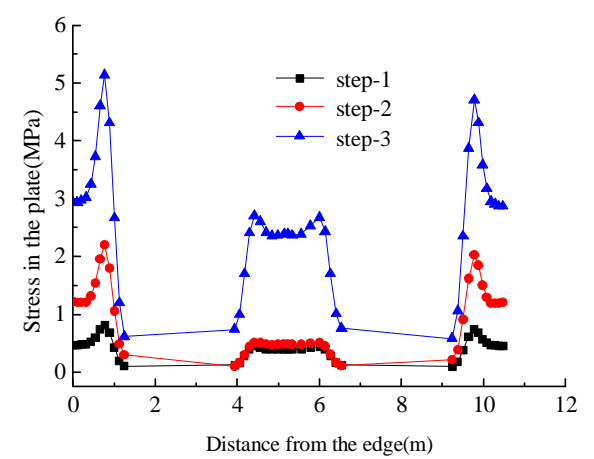

Fig.7 Stress curve along the Path-3 in the plate

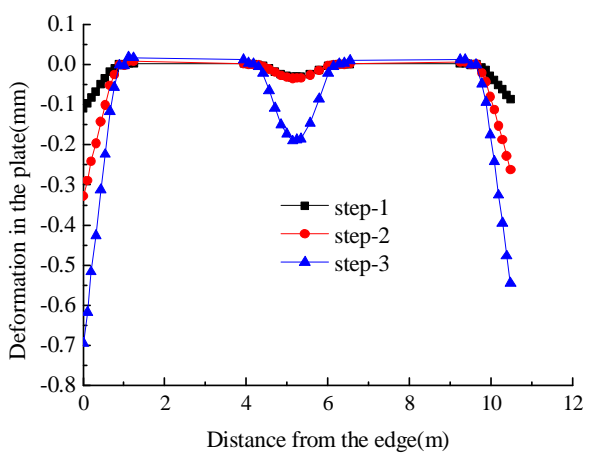

Fig.8 Deformation curve along the Path-3 in the plate

Analysis of the stress and deformation along path-4. It can be seen from Fig.9, the stress of plate edges is small in this direction. The stress between Reserve hole in edge of board and the board edge have little difference. The numerical of two reserved pile hole in the middle plate position after the first two steps loading is not big. But after applying weight of cover concrete, plate stress increases obviously which is more than two times the part of the edge stress. 
It can be seen from Fig.10, the vertical deformation of plate edges is the largest and deformation of two reserved hole of middle position follows. But upward vertical deformation appears on the edge of the reserved holes area, indicating that the local board position occurs up a slight warp.

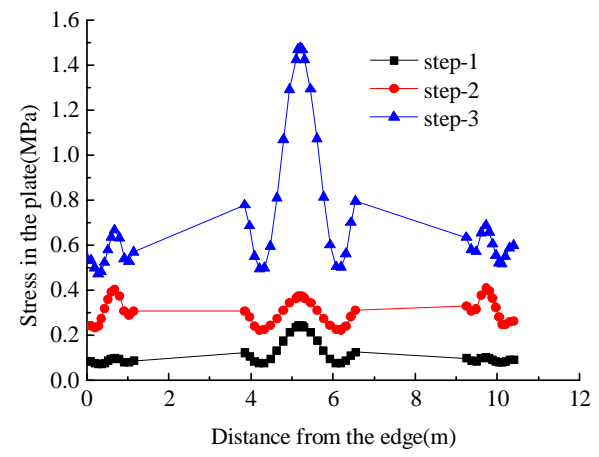

Fig.9 Stress curve along the Path-4 in the plate

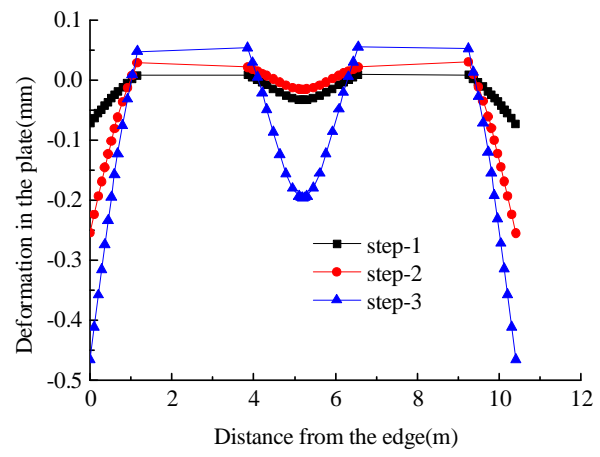

Fig.10 Deformation curve along the Path-4 in the plate

\section{Summary}

The analysis result shows that the stress distribution in plate is not uniform and the stress in the process of the reserved around pile hole is higher. In the process of construction, the local thickness of the concrete thick is $32 \mathrm{~cm}$ around the pile hole to ensure the safety of the construction process.

Yuanshui bridge uses precast reinforced concrete bottom template instead of steel template. It reduces the steel of steel boxed cofferdam in the input and makes full use of cover concrete design as cofferdam bottom to save project cost.

Approach of this project has achieved good economic benefits which can be reference for the similar engineering.

\section{References}

[1] Industry standard of PRC, The technical specification for construction of highway bridges construction (JTGF50-2011), S. China Communications Press. 2011. (In Chinese)

[2] K. Xiang, The steel boxed construction of concrete bottom slab in elevated pile cap in Changjiang tunnel bridge, J. Railway Engineering. 8(2010) 30-33. (In Chinese)

[3] J. Su, The study of finite-element analysis to the steel lifting caisson in deep-water foundation, D. Hefei University of Technology. (2010). (In Chinese)

[4] J.N. Li, L. Xian, H.G. Xie, Construction technology of steel boxed cofferdam on concrete floor in deep ocean area, J. Construction Technology. 5 (2012) 57-60. (In Chinese) 